\title{
Good-bye email, welcome Slack
}

\section{Juan Manuel López Zafra ${ }^{1}$, Sonia de Paz Cobo ${ }^{2}$, Ricardo A. Queralt Sánchez de las Matas $^{3}$}

${ }^{1}$ Métodos Cuantitativos, CUNEF, Spain, ${ }^{2}$ Economía Aplicada I e Historia e Instituciones Económicas, Universidad Rey Juan Carlos, Spain, ${ }^{3}$ Métodos Cuantitativos, CUNEF, Spain.

\begin{abstract}
Email is the standard in communication with university students; as a one-toone communication device, students repeat their doubts along multiple messages, multiplying the teacher's work and preventing the participation and learning of other students. The topic forums on virtual campuses allow better a management of doubts but require the active participation of all the students to achieve a final outcome. We propose to abandon the email and traditional forums of the campuses and enter tools with a higher professional profile to manage communication with the students. The results of this first experience, carried out with more than 90 postgraduate students, encourage its mass employment in both undergraduate and postgraduate. The survey conducted over 102 students in three different subjects of two different MSc shows how Slack, the tool we used, has been highly valued, with differences depending on the studies but neither on the gender nor on the intensity of use of the social networks.
\end{abstract}

Keywords: Communication; social networks; email; Slack. 


\section{Introduction}

University teaching, both in degree and postgraduate, is evolving with the integration of new technologies. We cannot pretend that our students, with access to global information in near real time, will be satisfied with traditional communication, which has historically occurred in the classroom and, or, in the teacher's offices, at the planned tutoring hours. Information arises at anytime, anywhere, and the need to resolve doubts is growing in the face of the enormous volume of information available. However, while it is true that on many occasions the urgency is not such, in many others rapid intervention is required to solve doubts and problems that should be, in fact, solved sooner.

Technological evolution is undeniable, and the incorporation of the younger ones into them is getting faster and faster. According to Pew (2018), in the US the smartphone penetration rate has risen from $35 \%$ in the 1st half of 2011 to $81 \%$ in the first quarter of $2019.96 \%$ for 18- to 29-year-olds own a smartphone, while only three out of four adults declare having a PC or laptop. Currently, the dependence of the smartphone has grown to important levels, with $22 \%$ of Americans between the ages of 18 and 29 reporting not having broadband at home but using a smartphone instead for their social and professional communications. The situation in Europe is similar. According to Eurostat (2019) 85\% of European households would have access to the internet, up from 55\% in 2007. It is interesting to note how the number of internet access in households with dependent children increases to $96 \%$. In Spain, and always according to the same report, $90 \%$ of young people aged 18 to 29 access the Internet daily. More than $80 \%$ of young Europeans in that age range (more than $95 \%$ for Spain) access the internet via smartphone. As regards the use of email as a means of communication, more than $85 \%$ of young Europeans in the previous age range report to do so on a regular basis, according to Eurostat (2019).

Email is the communication tool par excellence between teachers and students. However, there are several problems in relation to their use and effectiveness. Thus, Ha et al (2017) examined the effect that excessive connectivity of students could have on the effectiveness of emails. Through face-to-face interviews and self-administered survey/quantitative data, they found that students' rejection of the reading of emails was not so much due to social media as to over-communications through this route. University departments, student organizations, and faculty advisors' e-mails were most likely to be avoided, and they recommend both university administrators and academic advisors "to reconsider the e-mail communication to students, target at the instant communicator social media users, and use Facebook to create a strong sense of community and campus involvement for their students." Almost $40 \%$ of students said they don't always read emails from academic advisers, and $54 \%$ of students said the same about emails from the university or from academic departments. Among all students, email use (12.1\%) ranked behind social media (35.2\%) and texting $(50.2 \%)$, but ahead of phone calls $(2.2 \%)$. The most important findings 
of the study, in relation to the use of emails by students, were that $72 \%$ of students treat emails from student groups like spam, more than $50 \%$ of students don't always read emails from their institution or academic department, and nearly $40 \%$ of students don't always read emails from their advisors.

The privacy of life outside the classroom is one of the main challenges that lecturers face. Thus, Hillman et al (2019) maintain that it is unpredictable to handle in a different way the communication in real time with the students because, as the title of their paper graphically points out, "I have a life".

Dawkins (2019) reviewed 19 studies to confirm that academics are behind the industry when it comes to mass email evaluation and optimization strategies. He cites technological limitations of learning management systems (LMS) and the limited expertise of teaching staff as the main obstacles to more effective mass email at university.

Some other experiences have been set up to surpass email as a communication tool with the students.

López Zafra and de Paz (2014) showed how Twitter could be a powerful tool to communicate insights to students and engage them into the subject. As far as the second semester of 2010-2011 they started to communicate with the students in a course of Business Statistics in the Business Administration grade in a private school in Madrid, Spain. Twitter was seen as very powerful in motivating students in a field where they felt well. The latter observation in the line of what the CEO of Twitter Spain stated in the Talking About Twitter congress (Granada, Spain, June $22^{\text {nd }}$ and $23^{\text {rd }}$ ), according to de Paz Cobo and López Zafra (2015); accessing Twitter is via mobile by $85 \%$ of young users. That is, by demographic target and usability it seems that Twitter can be a tool with which to connect with the students of the university.

Twitter is formed as a social network whose teaching use can be very productive. According to the experience of its use in the classroom over five years, always in subjects of the quantitative area and in different schools, De Paz Cobo et al (2017) found that students demand more and more alternative means of communication to the traditional ones. Access to sources of information in many different formats (text, audio, video) on the Internet, with the additional feature of the constant renewal of content, requires the use of a tool with the maximum accessibility, dissemination, immediacy and versatility, as well as the most important of them all: to be accepted almost natively by students

Of course, Facebook has also been widely evaluated both as a communication and learning tool. Walsh (2010) was one of the first in announcing the possibilities of the, then, increasing in importance network; he states a comment by Kristen Nicole Cardon, lecturer of a British Literary History course, where she describes the advantages of using Facebook 
in the classroom, such as motivation, pointing at matters that really care and not wasting time in those already understood, the possibility of getting insights from those who generally don't participate in the discussion and the wider perspective coming from more and more students. Duncan and Barcyczk (2015) found that students in the Facebookenhanced courses reported having more favorable attitudes toward the social media and a slight increase in their sense of classroom community compared to students in nonFacebook-enhanced courses.

The rise of Instagram (IG) has also been the subject of use in the classroom. Instagram, owned by Facebook, has 1 billion monthly and over 500 million daily active users; of those, $71 \%$ are under age 35 , proving that Instagram is one of the most widely used social networks by young people, the target group of a college class. Time spent is nearly just 5 minutes behind the almost daily hour spent on Facebook. Byrd and Denney (2018) report the success of that social network in a journalism course. Results showed by Arceneaux and Dinu (2018) proved that information retention was most improved by visually based information published by professional news outlets, after an experimental design confronting Twitter to Instagram. De Paz Cobo and López Zafra (2020) have been using IG during the first semester of the 2019-2020 course, showing a higher engagement of the students and increase of the interactions regarding those in Twitter.

Anyway, it seems that email will continue to reign as in the top of the digital communication system. According to Becker (2016), it's going to be very difficult to substitute a tool that has been evolving over 30 years, with around 3 billion users in 2019, with an expectation of 319 billion emails sent in 2021 (Campaign Monitor, 2019), the third most influential source of information for B2B audiences, behind only colleague recommendations and industry-specific thought leaders (Finn, 2019). The main problem we have experienced as long-time users of Twitter and early adopters of Instagram is the difficulty in managing in a professional way the feedback of the students, their doubts and problems. In the search of improving the latter, trying to overcome email avoidance and engaging students in a two-sense communication system, we decided to enter Slack.

\section{Slack in the classroom}

As explained by Woodgate (2019), Slack is a workplace communication tool, "a single place for messaging, tools and files.” This means Slack is an instant messaging system with lots of add-ins for other workplace tools. The add-ins aren't necessary to use Slack, though, because the main functionality is all about talking to other people. There are two methods of chat in Slack: channels (group chat), and direct message or DM (person-to-person chat). With over 12 million daily active users (Chan, 2019), Slack is close behind Microsoft Teams, its main competitor. 
Being a slightly young communication tool (the first version was out during 2013 while Facebook was founded back in 2004, Twitter in 2006 and Instagram in 2010, and email in place since mid-seventies), and clearly leaning on the professional market, no so many experiences have been reported on the matter. Talbot (2015) is one of the early adopters of Slack in teaching, because of the artificiality of the discussion rooms in former LMS, the not-so-easy to share rich content such as videos in the LMS, and finally because the lack of efficiency when compared to email or SMS in the one-to-one communication. Talbot stresses the email-free possibilities of Slack as one of the motivating issues for adopting the tool, along with the increase in the amount of communication; students' perceptions were mostly favorable. Peck (2018) describes his first year as a professor as a terrible administration time, spending hours in checking, reading and answering often redundant emails. He chose Slack because of the possibility of shifting conversations out of the inbox, into a platform where they could be easily met any time during the semester, the possibility of answering once every issue and, a very important matter, the possibility of Teckchandani (2018) describes how Slack works, stating that the free version is enough for the classroom. Hussain et al (2018) compare the use of WhatsApp groups to Slack for classroom activity; although they expected undergraduate students would use Slack heavily, their usage habits suggested the application was not as effective as other research has shown it to be at the graduate level.

We decided to promote the effective use of Slack in four different postgrad classes in two different MSc, two into the Master's Program in Data Science for Finance (MDSF; courses in Reduction and Segmentation Techniques, on one hand, and Forecasting, on the other, with the same 21 students in each course) and another two in the Master's Program in Financial Markets (MMF; two different classes with a total of 60 students in a course in Quantitative Methods for Business). The scope of the master programs is different but both groups of courses share as a common feature the strong use of programming languages, in particular the $\mathrm{R}$ software. The page mdsf.slack.com was built to communicate with the students of the MDSF and the finanzascuantitativas.slack.com with those in the MMF. In every Slack page, four general threads were built: \#general, for communication of whatever the issue in any course; \#not_everything_is_somthg (where somthg stands for finance, in the case of the MMF, and data_science in the other case), a very popular thread among students where talking about anything, related or not to the course, was promoted; and a specific thread for each subject: \#quantitative_finance in the MMF and \#segmentation and \#forecasting in the MDSF. The Direct Messaging possibilities of Slack were also used to solve particular problems.

Slack retrieved a quite heavy use of the platform, specifically among the MDSF students. As of January $23^{\text {rd }}$, and with days before the final exams, 3.129 messages out of the maximum 10.000 that the free version allows where crossed in the different channels of the 
MDSF area. The weekly traffic (measured in terms of active users, those with at least an open channel) was intense, with all the students reading messages and the half publishing messages every week except during the Christmas period. \#forecasting was the preferred thread, with 134 published messages, followed by \#general with 76, \#segmentation with 40 and \#\#not_everything_is_data_science with 9. The same statistics in the MMF showed 914 messages (so one third, for over three times the number of students), a quite lower weekly traffic, descending in terms of active users as the course was advancing, 179 messages published under the \#quantitative_finance thread, 98 under the \#not_everything_is_finance one, and 9 under the \#general one.

We conducted a survey among the users for understanding both their behavior and the experience. 102 Students of the three different subjects were asked about different aspects of the use of Slack through a Google Form. 89 (87.25\%) of them answered, 48 from the Quantitative Finance subject in the MMF and the remaining 41 in the subjects of Reduction and Segmentation Techniques and Forecasting in the MDSF. For 95\% of them, it was their first experience with Slack in the classroom, and $77.3 \%$ of them heard about Slack for the first time in our subjects. A tiny $15 \%$ of them (20\% among the MDSF students) had a Slack account prior to the present experience.

In a 5 point scale, where 1 means "totally disagree" and 5 "completely agree", the Slack global experience graded 3.78 points, but just 3.29 among those in the MMF for a 4.39 among those in the MDSF, showing possibly that Slack is better suited for those in technical studies; remember that the use of the tool among these students was quite heavier. The sentence "I love Slack" hit an average of 3.2 points but falling down to 2.71 among the students in the MMF and jumping up to 3.8 among those in the MDSF. No significant differences were found in terms of gender.

It's quite interesting the fact that the sentence "I think Slack is an interesting communication tool for the university" is valued with 4.1 out of 5 points (just 3.71 for those in the MMF, while the MDSF students increased the grade up to 4.55) and "Slack should be used by the remaining lecturers" get 3.98 points out of 5 (again, a lower value of 3.5 among those studying the MMF for a 4.55 among those in the MDSF studies).

In terms of use of social networks, all but one were WhatsApp users, 78.7\% IG, 71\% FB and $50 \%$ Twitter. $84.3 \%$ of them declared accessing their social networks more than once daily. The number of different social networks and the intensity of use didn't not cause any effect on the previous results. 


\section{Conclusion}

Following previous experiences with Twitter and a parallel one with Instagram with undergraduate students, we decided to enroll four different classes in two master programs under the professional, workplace communication tool Slack. The results are different according to the profile of the programs. The those following the master's in data science were much more active and heavier users than their mates in the master's in finance, even if the different courses share the common feature of intense use of the R statistical software. As the survey proved, Slack was a good alternative to email and the usual forums in the LMS. The experience was enjoyed by the students, and as lecturers we were able to reduce the volume of emails along with the possibility of focusing the problems in a professional platform.

\section{References}

Becker, M. (2016) Facebook vs. Email: Why email reigns supreme (and always will). The business journals. June 27. https://www.bizjournals.com/bizjournals/howto/technology/2016/06/facebook-vs-email-why-email-reigns-supreme.html

Byrd, R.; Denney, P. (2018) "Using Their Own Voice": Learning to Tell Stories with Instagram. Teaching Journalism \& Mass Communication, Vol. 8, no. 2, pp. 47-55

Campaign Monitor (2019) How Many Email Users Are There in 2019? https://www.campaignmonitor.com/resources/knowledge-base/how-many-email-usersare-there-in-2019/

Cahn, R. (2019) Slack says that while its user numbers still lag Microsoft's, what really matters is that users love its app a lot. Business Insider, Oct 10. https://www.businessinsider.com/slack-daily-active-users-microsoft-teams-201910 ? IR=T

Dawkins, R. (2019) Mass email at university: current literature and tactics for future use. Open Learning: The Journal of Open, Distance and e-Learning. Volume 34, Issue 3.

Duncan, D.; Barczyk, C. (2015) The Facebook Effect in University Classrooms: A Study of Attitudes and Sense of Community Using an Independent Measures Control Group Design. American Journal of Management, Vol. 15 (3), pp. 11-22

Eurostat (2019) Being young in Europetoday - digital world. https://ec.europa.eu/eurostat/statistics-explained/pdfscache/39761.pdf

Ha, L.; Joa, C.; Gabay, I.; Kim, K. (2017). Does College Students' Social Media Use Affect School E-Mail Avoidance and Campus Involvement? Internet Research. 28. 00-00. 10.1108/IntR-11-2016-0346.

Hillman, S.; Hillman, A.; Neustaedter, C. Pang, C. (2019) "I Have a Life": Teacher Communication \& Management Outside the Classroom. CHI EA '19: Extended Abstracts of the 2019 CHI Conference on Human Factors in Computing Systems 
Hussain, S.; Mills, A.; Sanders, A. (2018) Use of Slack in the Undergraduate Classroom as a Means of Fostering Student/Faculty Engagement. Qatar Foundation Annual Research Conference Proceedings, Volume 2018 Issue 4, March.

Finn, A. (2019) 35 Face-Melting Email Marketing Stats for 2018. The WordStream Blog. https://www.wordstream.com/blog/ws/2017/06/29/email-marketing-statistics

López Zafra, JM; de Paz Cobo, S; (2014). Twitter as a learning tool in higher education. 9th International Congress on Teaching Statistics. Flagstaff, Arizona, EEUU, 13-18 Jul 2014.

De Paz Cobo, S.; López Zafra, JM (2015). Aplicación de Twitter a un curso de estadística en el Grado de Administración y Dirección de Empresas. Actas de las VI Jornadas en Innovación y TIC Educativas. JITICE 2015, 13-16.

De Paz Cobo, S.; López Zafra, JM.; Queralt, R. (2017). Docencia 3.0: Twitter en el aula. In Gertrudix, Esteban, Gálvez de la Cuesta and Rivas (Eds) LA innovación educativa como agente de transformación digital en la educación superior. Acciones para el cambio. Dykinson, Madrid, pp. 187-198

De Paz Cobo, S.; López Zafra, JM (2020). Y ahora... Instagram en el aula. JID (in press)

Peck, E. (2018) How I Use Slack in My Courses - a 3 Year Reflection. Medium. https://medium.com/bucknell-hci/how-i-use-slack-in-my-courses-a-3-year-reflection$888 \mathrm{c} 7 \mathrm{e} 742 \mathrm{~d} 04$

Pew (2018) Mobile Fact Sheet: Internet/Broadband. Pew Research Center, February 5, 2018, http://www.pewinternet.org/fact-sheet/mobile/

Talbot, B. (2015) Slack: Solution to Persistent Issues in Online Teaching? Medium. https://medium.com/@Bud_T/slack-solution-to-persistent-issues-in-online-teaching492b60d6ff0e

Teckchandani, A. (2018) Slack: A Unified Communications Platform to Improve Team Collaboration. Academy of Management Learning \& Education Vol. 17, No. 2

Walsh, K. (2010). Facebook as an Instructional Technology Tool. https://www.emergingedtech.com/2010/08/facebook-as-an-instructional-technologytool/

Woodgate, R. (2019) What Is Slack, and Why Do People Love It? How-to-geek, July 17. https://www.howtogeek.com/428046/what-is-slack-and-why-do-people-love-it/ 